\title{
The urban food question in the context of inequality and dietary change: A study of schoolchildren in Accra
}

Sara Stevano, Deborah Johnston, Emmanuel Codjoe

\section{Abstract}

Diets are changing globally, as agricultural and food systems have become globalised. Understanding how patterns of globalisation affect welfare is a key development question, but we know little about the way that the globalisation of food systems impacts different groups. This study explores food security and consumption among schoolchildren in Accra. We use a novel approach based on triangulation of primary data on food consumption and a synthesis of secondary literature on food trade, policy and urban food environment. Thus, we bridge a divide between micro-level analyses of food consumption and macro-level studies of food systems. We find that socio-economic status is a critical dimension, with poorer children more vulnerable to food insecurity and narrow dietary diversity. However, consumption of packaged and processed foods, often sugar-rich and nutrient-poor, cuts across wealth groups. We argue that the urban food question today is defined by two intersecting phenomena: inequality and dietary change. The urban poor continue to face the fundamental challenge of adequate food access amidst a food environment that provides consumers with unhealthy and cheap food options. Therefore food policy needs to regulate imports of cheap, unhealthy and enticing food.

Keywords: food consumption, food security, food systems, inequality, Ghana 


\section{Introduction}

Urban diets are changing, as agricultural and food systems have become globalised and created new forms of food production, distribution, and trade (Hawkes et al. 2010, Lerner et al. 2014). The nutritional implications for the Global South are seen in rising obesity and non-communicable diseases alongside persisting food insecurity and old-fashioned food policies (Popkin et al. 2012; Masters et al. 2018). Understanding how patterns of globalisation affect the welfare of populations is a key development question, but we know little about the way that the globalisation of food and agriculture systems affect different individuals or groups. Hawkes (2006) has suggested that dietary change will be experienced differently by rich and poor, by urban and rural populations. However, more context-specific evidence is needed to capture the complexity of impacts, and to frame the urban food question in the economic, social and political factors that shape urban food systems.

This study explores food consumption among schoolchildren from different socio-economic backgrounds in Accra, using a novel approach based on triangulation of primary quantitative and qualitative data on food consumption and a synthesis of secondary literature on food trade, policy and urban food environment. Thus we bridge a divide between micro-level analyses of food consumption and macro-level studies of food systems. This paper has two main objectives. First, it seeks to extend the literature on urban food consumption through a case study of schoolchildren, given the gap that persists in our knowledge on food access in the urban South (Floro and Swain 2013; Lagerkvist et al. 2013). Second, the paper interrogates the urban food question today, in the context of rising inequality and global dietary change. Thus it engages with studies on inequality (Kollamparambil 2017; Agyre-Tettey et al. 2018) and on the nature of urban food security in African cities in the 1990s (Levin et al. 1999; Maxwell 1999; Maxwell et al. 2000). Finally, this paper proposes that to better understand urban food consumption, we need an integration of the research approaches used in public health and the political economy of food provisioning. 
We find that socio-economic status is a critical dimension of food consumption, with poorer children more vulnerable to food insecurity and narrow dietary diversity. However, consumption of packaged and processed foods, often sugar-rich and nutrient-poor, cuts across wealth groups. This illustrates the widespread desirability and availability of cheap, ultra-processed foods, with concomitant implications for future welfare of urban populations in developing countries (Monteiro et al 2013). Thus industrial and trade policies that regulate food processing and content, as well as production and imports of cheap unhealthy foods are much needed.

The next section provides the background on agricultural policy, urban food security and dietary change in Ghana, highlighting how concerns about urban food security have changed over time. The third section describes the study setting and the methodology. The fourth section presents the findings on urban food provisioning (4.1), food security (4.2), food consumption (4.3) and food knowledge (4.4). The final section discusses the results and concludes.

\section{Agricultural policy, dietary change and urban food security in Ghana}

Between 1970 and 1982, agricultural policy in Ghana had at its core Operation Feed Yourself $(\mathrm{OFY})$, aimed at increased production of maize and rice to achieve national food self-sufficiency, especially for the growing urban population and the industrial sector (Girdner et al. 1980; Nyanteng and Seini 2000). Rice production increased and cocoa production, previously the dominant export crop, declined (Nyanteng and Seini 2000). Girdner et al. (1980) argue that, while agricultural policy of the 1970s promoted domestic food production, Ghana remained overly reliant on colonial export commodities - cocoa and palm oil - and, by consequence, had to pay a high bill for food imports.

The Ghanaian economy was hit by macroeconomic and political instability in the second half of the 1970s, which resulted in urban protests driven by food shortages and high food prices (Maxwell 1999) and led to the implementation of the Economic Recovery Programme (ERP) in 1983, a set of reforms supported by the International Monetary Fund. At first, the ERP for the agricultural 
sector sought to maintain self-sufficiency in cereals production but also to boost cocoa exports (Nyanteng and Seini 2000). In later phases of the programme, focus shifted to non-traditional export crops due to decline of traditional commodity prices (Ouma 2015; Amanor and Chichava 2016). With the removal of agricultural subsidies and later expansion of export horticulture, food imports continued to grow (Amanor and Chichava 2016).

Structural adjustment also caused rising unemployment and declining urban wages, thus affecting urban population's ability to buy food (Maxwell 1999). In Accra, households responded by diversifying income sources and taking up various paid jobs and cash-earning activities in the informal economy (Levin 1999; Maxwell 1999). Women's increased participation in incomegenerating activities, such as petty trading and food preparation for sale, and increasing prominence of street food have been seen as outcomes of this period of economic liberalisation (Ibid.).

Thus reliance on food imports and informalisation of employment, which has shaped food supply in urban areas through, inter alia, the expansion of street food and imported (packaged) foods, are key features of the Ghanaian food environment from the 1990s to the present. Based on broad national data, we know that Ghana produces approximately 50 per cent of its cereal and meat needs and spends one billion USD on food imports (Amanor and Chichava 2016). While the country is estimated to be self-sufficient in maize, cassava and yam production, it is dependent on imports of wheat and rice (Cudjoe et al. 2010). Over 70 per cent of rice, now the major staple in Ghana, is imported mostly from Thailand and Vietnam (Amanor 2015). Cudjoe et al. (2010) find that during the 2007-2008 food crisis, when international prices of wheat and rice sharply increased, the urban poor were the hardest hit because urban food prices follow more closely the movements of world prices. Thus the food crisis has exposed the country's vulnerability due to dependence on food imports, and that the urban poor are at risk of food insecurity. 
What are the implications for patterns of urban diets? Over the past few decades, progress in reducing hunger and undernutrition has been remarkable in Ghana, with the Global Hunger Index (GHI) decreasing from 42.7 in 1992 to 13.9 in 2016 (GHI 2016). ${ }^{i}$ Regional data suggest that child undernutrition is highest in the poorer regions of the North and lowest in Greater Accra (Demographic and Health Survey [DHS] 2014). At the same time, overweight and obesity are increasing (Ofori-Asenso et al. 2016). Overnutrition appears to affect predominantly urban and wealthier individuals, and it is higher among women than men (DHS 2014). However, national and regional averages do not illuminate the pathways of change and leave us with no tools to identify the most vulnerable.

Dietary change is underway in Ghana. Broad brush estimates suggest that staple consumption is changing in composition, with greater prevalence of rice, which shows increasing trends in both production and imports, especially in the early 2000s (FAOSTAT). However, the share of dietary energy supply derived from cereals, roots and tubers is decreasing (Ibid.), which indicates that diets are becoming less reliant on cereals and more reliant on other foodstuff. ${ }^{\text {ii }}$ This is in line with data on caloric intake on developing countries as a group suggesting that relative importance of cereals is stagnant or decreasing, and that of vegetable oils, sugar and meat is increasing (Food and Agriculture Organisation [FAO] 2015). In addition, staple consumption is shifting towards rice, with increasing trends in rice production and imports (FAOSTAT). National-level data on food trade in Ghana also indicate that imports of milk, dairy products, poultry and sugar are on an upward trend since the mid-1990s. Imports of vegetable oils and fruit have exceeded exports since the early 2000s (FAOSTAT). These patterns may suggest that diets are diversifying; however, there are also concerns about the deterioration of diet quality, with increased consumption of sugar-rich, nutrient-poor and ultra-processed foods, which is in turn linked inter alia to globalisation and liberalisation of food trade (Hawkes 2006; Hawkes and Murphy 2010). Between 1990 and 2010, diets changed in contradictory ways, with some dietary patterns showing higher consumption of healthy foods and others based on greater intake of unhealthy foods (Imamura et al., 2015). 
Middle-income countries, of which Ghana is part, embody this ambivalence by showing the worst shifts in terms of increased consumption of unhealthy foods, but also improvements in consumption of healthy foods (Ibid.). In Ghana, the market value of packaged food ${ }^{\text {iii }}$ tripled between 2012 and 2018 and is forecasted to grow at one of the highest rates worldwide; currently, snacks make up one third of the total market value for packaged foods (Euromonitor International). Per-capita expenditure on packaged food almost doubled since 2004 (160 USD in 2018) and is now remarkably higher than in Nigeria (32 USD) (Ibid.).

In 2010, Ghana attained lower middle-income country status (Jerven 2016) and is considered by many as a success story given sustained GDP growth and good performance on human development indicators (Cooke et al. 2016). This has contributed to the emergence, or expansion, of the so-called middle class (Luckman et al. 2005). However, as Lentz (2015) describes, much of the Ghanaian middle class laments it cannot make ends meet. The story of success has come under serious threat due to collapse in export revenues for oil, cocoa and gold in recent years, and a worsening fiscal position. ${ }^{\text {iv }}$ This was accompanied by increase in prices of fuel, water and electricity paid by consumers, resulting in malcontent and urban protests. Economic downturn and rising cost of living are concerning especially for the poorer population, and for the impact on poverty and inequality. While poverty rates have fallen, inequality in Ghana has been on the rise since the early 1990s, with the most vulnerable social class continuing to expand much more strongly than other social groups in 2012-2017 (Annim et al. 2012; Obeng-Odoom 2012; Cooke et al. 2016; Agyre-Tettey et al. 2018; Euromonitor International).

The Greater Accra Region shows the fastest-growing consumer expenditure as well as the lowest levels of poverty and intra-regional inequality nationally, with poverty incidence at 2.6 per cent and a GINI coefficient of 35.4 (GSS 2015; Euromonitor International). However, these statistics hide dynamics of inequality that are visible only at the micro-level, beyond the level of the region or district. For instance, Obeng-Odoom (2012) suggests that inequality in Accra has been driven by 
in-migration of poorer people from other urban and rural areas. Studies of the housing market in Accra highlight precarious conditions, with rents gradually increasing and a lump-sum payment system of one or more years of advance rent that is particularly daunting for the poor (Arku et al. 2012). Earlier studies of livelihoods in Accra find that many households are vulnerable due to lowpaid jobs and informalised, unsecure employment (Maxwell et al. 2000). Thus, low levels of poverty in the Greater Accra Region, relative to other regions, obscure intra-regional and intraurban vulnerabilities.

Against this background, we will seek to integrate the analysis of food security and consumption in the functioning of urban food systems. Debates on urban food security in the late 1990s, as illustrated by Maxwell (1999), were concerned with making urban food security visible as a political issue in the context of urban poverty. The emphasis on urban poverty was renewed in the aftermath of the 2007 food crisis, when the food price shock brought to light the fragility of food security, especially for the urban poor. While urban poverty continues to need attention, due to rapid urbanisation and scarcity of decent employment across urban areas in the Global South (Floro and Swain 2013), we argue that it is now also necessary to look at the urban food question in the context of dietary change and changing food quality. It is necessary to capture the complexity of food consumption, by analysing the micro-level dynamics of urban food sourcing practices and food consumption. This overview provides the broader context in which our micro-level analysis of urban food security and food consumption among schoolchildren is to be situated.

\section{Study setting and methods}

This study explores vulnerability through the lens of inequality in food consumption among schoolchildren in Accra. The findings presented in this paper are based on triangulation of primary and secondary data, which were collected and analysed between 2015 and 2017. Primary data collection consisted of a student survey and qualitative focus groups with schoolchildren in five Junior High Schools (JHS) in the Accra Metropolitan Area. In addition, throughout field research, 
semi-structured interviews were conducted with representatives of key governmental and nongovernmental organisations as well as the food industry. A summary of the methods for primary data collection is provided in the table below, and the methodology used for interviewing schoolchildren is described in turn.

Table 1 here

Selection of schools, student survey and focus groups

Having gained permission from the Ghana Education Service (GES) to conduct research activities in JHS, we selected four schools in the Accra Metropolitan Area (AMA). Using key informant interviews and criteria such as school type (i.e. public or private), location, indicators of minimum teaching equipment and school's infrastructure ${ }^{v}$, the selection aimed to choose schools attended by children from different socio-economic backgrounds. Table 2 illustrates our selection, which represents a wide range, from a public school attended by many children in Nima, a lower-class neighbourhood in Accra (Aguda 2009), to a top private school charging tuition fees in USD. ${ }^{\mathrm{vi}}$

Table 2 here

Respondents were selected randomly and the process was facilitated by teachers in each school. ${ }^{\text {vii }}$ We planned to conduct at least 30 structured interviews in each school. However, we could not complete all interviews at AIS and therefore added a fifth school, Tema International School (TIS), which is also a top private and boarding school. The overall sample is as reported in the table below.

Table 3 here

The questionnaire was composed of the following components: basic demographic information, child's assets, food security questions, child dietary diversity score, food knowledge and consumption questions. We measure children's diets through indicators of food security, dietary 
diversity and food consumption, and link these to food provisioning practices, which told us more about the structural features of the urban food system.

Based on a preliminary analysis of survey data, a sub-sample of 63 schoolchildren across the four schools in AMA were selected to take part in a series of qualitative focus groups grouped on three themes. Focus group 1 looked at patterns of intra-urban mobility and food acquisition practices. Focus group 2 explored the theme of children's exposure to food advertising and food preferences. Focus group 3 investigated children's food and nutrition knowledge, trying to discern whether knowledge shapes consumption.

\section{Child asset index}

Literature on child-based interviews discusses the challenges of measuring child poverty as children may not have good knowledge of household income, consumption or assets (Gordon et al. 2003; Hannum et al. 2016). One route is to collect data on children's assets, which minimises measurement errors (Ibid.). In this approach, an indicator based on children's assets is a proxy of underlying household welfare (i.e. we assume that the child asset index varies with underlying household wealth), rather than the choice of asset that directly produce welfare (c.f. Johnston and Abreu 2016). As such this is not a measure of child deprivation but a measure that correlates with household wealth. We collected data on a set of assets that children have direct access to - books, tablet, computer, dvd player, smartphone, video game console and own bedroom - and constructed a child's asset index using principal component analysis (PCA) (Filmer and Pritchett 2001, Wall and Johnston 2008 and Abreu 2012). The sample was then grouped in wealth quintiles based on the asset index.

\section{Food and diet indicators}

We use four key indicators to analyse food consumption and diets: one on access to food, two on diet quality and one on food knowledge. First, to assess food security we follow the approach used 
by the WHO Global School-Based Student Health Survey (WHO 2012), which consists of two questions: one on going hungry and one on having breakfast, with associated frequencies. Second, as proxies for diet quality, we use a standard dietary diversity indicator, based on $24 \mathrm{~h}$ recall (Ruel 2002; Arimond et al. 2010; FAO 2010) and, in addition, an adapted version of the World Food Programme's (WFP) Food Consumption Score (FCS) (WFP 2008), which captures the consumption frequency of particular food items in the seven days before the interview. ${ }^{\text {viii }}$ Finally, we considered food knowledge, as food and nutrition knowledge is often is a core component of nutrition interventions targeting schoolchildren or mothers (Adelman et al. 2008; Imdad et al. 2011), and defined it as an awareness of key healthy foods, such as fruit and vegetables, or basic nutrition facts, such as the importance of balanced diets and nutrient intake.

A central motivation of our analysis is to explore the association between dietary practices and socio-economic status, as measured by the child asset index. Thus, we explore associations between food indicators and wealth and conduct a basic regression analysis to sketch how age, gender, wealth and food knowledge may be associated with measures of diet quality. However, as this analysis alone is limited, we bring together qualitative insights on the food environment to reach a fuller understanding of food inequalities.

\section{Results}

\subsection{Sites and means of schoolchildren's urban food provisioning}

The school is a central and heterogeneous site for children's school provisioning. The private schools in our study have a canteen. In AIS, the canteen is run by a catering company and has a monthly menu with options selected in advance by children or their families. The canteen meal includes fruit or dessert, and vegetables as sides. Children can also buy snacks at break times from the canteen. In Jack \& Jill, however, children can buy snacks and drinks from vendors on the school's premises, and in their canteen, children buy food by piece, not by meal. Thus the practice 
of pricing food by item, rather than by meal, implies that children buying food from the same canteen have varying types and quantities of food.

In public schools, there are no canteens, and stationary food vendors operate within the school's premises and in the surrounding areas. Where options are limited at school, children prefer to go to the street food vendors in the school's surroundings. ${ }^{\mathrm{ix}}$ Children may also buy food before entering the school in the morning. For example, at Osu Presby, it was common among schoolchildren to buy porridge from the stall in front of the school in the morning. Besides permanent food stalls in the proximity of schools, public schools tend to be a target of mobile food vendors, as we will discuss in more detail later.

Street food, defined as 'any ready to eat food or beverage sold and sometimes prepared in outdoor public spaces by vendors or cooks, either itinerant or stationary, either on foot or from mobile outlets' (FAO 2016: 1), is central to urban children's food provisioning, providing much of the food consumed, particularly in public schools. Street food employs an estimated 60,000 individuals in Accra, many of whom are women, and its ubiquitous presence has directed attention to issues of food hygiene and safety (Ackah et al. 2011; FAO 2016). A high number of children in the sample, 72.6 per cent, had purchased street food at least once in the week before the interview. Interestingly, street food is especially important for children from poorer backgrounds, with 60 per cent and 75 per cent of children in the two poorest quintiles, respectively, who had bought street food more than once in the previous week.

How do children purchase food? Most children in the sample, everyone except from children at AIS and TIS, buy food for themselves with chop money. This is money handed out on a daily basis, unless the families cannot afford to do so daily, ${ }^{\mathrm{x}}$ and serves the specific purpose of buying food, and in some cases for other expenses, such as transportation. The amount of chop money ranges from 1 or 2 GHS to 10 GHS per day, the average is 5 GHS/day. In contrast, children at AIS receive pocket money, which is handed out mostly weekly and not used to buy meals. Meals are 
paid for by families in advance and therefore children can use pocket money to buy some snacks. In focus groups at AIS, children explained that they use pocket money to buy food when they go to shopping malls with friends at weekends. This is a substantial difference for children from different socio-economic backgrounds and one that has direct implications on the quantity and quality of food consumed.

\subsection{Food security}

The majority of children in the sample, 76 per cent, have not gone hungry due to lack of food in the month before the interview. However, a remarkable 24 per cent of the sample reported that they felt hungry once or a few times due to lack of food. In a context characterised by the lowest levels of undernutrition in the country, this finding stands out. This result shows that inability to access sufficient quantities of food does occur among schoolchildren in Accra, thus suggesting that urban food insecurity is an issue that needs attention. ${ }^{\mathrm{xi}}$

Who are the food insecure children? Looking at the association between food insecurity and wealth, we observe that most food insecure children are in the poorer quintiles. We find a negative and statistically significant association ( $\mathrm{p}$-value $=0.065$ ) between food insecurity and wealth. The question on breakfast reveals that the majority of children interviewed, 68 per cent, have breakfast before going to school. However, a significant 32 per cent of children in the sample go to school without breakfast. Many of these children buy breakfast on their way to school, from street food vendors, or at school from the school canteen or on-site vendors. With the focus groups, we explored some of the reasons for not having breakfast at home. Children mentioned a variety of factors that may prima facie appear to reflect family's practices and habits. For example, some children said they have to wake up very early to arrive at school on time and therefore indicated lack of time as the reason for not having breakfast at home, others said their parents do not prepare breakfast at home and instead give them money to buy breakfast on their way to school. However, 
we also find a negative association ( $\mathrm{p}$-value $=0.000$ ) between not having breakfast before going to school and wealth, with the majority of children in this group in the two poorest quintiles.

This finding suggests that reasons mentioned for not having breakfast may conceal an underlying link with socio-economic status. Having to wake up very early in the morning may reflect the location and housing conditions of children's homes, how they go to school, their parents' occupations, and their roles within their households. For example, we find that 93.5 per cent of children in public schools walk to school while this percentage drops to only 10.4 per cent of children in private schools, as more than half of them are driven to schools. This shapes where children acquire food, with food vendors concentrating in proximity of public schools.

With regard to food security, a key concern is the timing of the first meal. On the day before the interview $53.4 \%$ of the sample had breakfast by $7: 30$ while the rest of the sample had their first meal between 8:00 and 13:00. There was a group of children, 15 per cent, who had their first meal at the first school break, around 10:00 or later. Most of these children are in the two poorest wealth quintiles. This may reflect the lack of resources to have two meals in the morning, resulting in the practice of postponing breakfast.

\subsection{Diet quality}

The dietary diversity indicator captures high consumption for cereals $(99.3 \%)$, oils and fats $(65.5 \%)$, sweets $(50.4 \%)$, meat $(48.2 \%)$, vegetables $(48.2 \%)$ and dairy products $(43.9 \%)$. Instead very low levels of consumption were recorded for vitamin-A-rich fruit and vegetables $(3.6 \%$ and $9.4 \%$, respectively) and nuts and seeds (9.4\%). We find a positive and statistically significant association between dietary diversity and wealth $(\mathrm{p}$-value $=0.007)$.

The FCS is associated positively with wealth, with a high level of statistical significance (p-value = 0.000). This suggests that children in wealthier quintiles consume healthier foods. In particular, we see that dairy and vegetables consumption increases in frequency with wealth. However, for other 
food items the association with wealth is not clear-cut. In particular this appears to be the case for foods and drinks that are consumed as snacks. Consumption of packaged snacks and carbonated drinks appears to cut across wealth quintiles, with poorer and wealthier children reporting similar levels of consumption. We argue that these forms of food consumption reflect the widespread availability and relative affordability of these foods. Packaged snacks and soft drinks are sold by food vendors on the schools' premises or in surrounding areas. Prices are such that most children can afford to buy these foods, at least occasionally. Indeed packaged snacks and soft drinks are among the cheapest foods at school or on the road.

To provide an example, we briefly discuss FanMilk snacks. FanMilk is a multinational that has been present in Ghana since the 1960s. FanMilk's distribution structure relies on thousands of mobile street vendors operating particularly in urban areas. ${ }^{\text {xii }}$ Its main products are a range of packaged frozen snacks, which may be yoghurt-based, chocolate-based or have a fruit flavour. In interviews conducted with FanMilk vendors, it emerged that many vendors go to public schools at break times and at the end of the school day. According to the vendors, FanMilk snacks are popular among children, which is confirmed by 72.7 per cent of children in our sample reporting having eaten FanMilk snacks in the previous week, with the highest consumption frequency found in the middle wealth quintiles. Children use their chop or pocket money to buy these snacks that are widely available and relatively affordable. These snacks are less available to children in top private schools because food vendors are not allowed to operate on the school's premises and proximity. Conversely, children from the poorest quintile can easily find these snacks at school but the lower frequency reflects smaller amounts of chop money. At times, vendors cut the snacks in half so that two children can share the cost. This example provides a glimpse on the functioning of the urban food system where food companies make use of informal channels to boost sales of affordable and widely available packaged foods.

\subsection{Food knowledge}


The majority of children in the sample (67.7 per cent) have basic food knowledge. The association between food knowledge and wealth is positive but statistically insignificant $(\mathrm{p}$-value $=0.107)$. It is however unlikely that the association is driven by the quality of nutrition education at school, as children in AIS and TIS, over-represented in the wealthiest quintile, do not have home science classes while all other children in the sample do. For example, in Osu Presby Girls, children were well aware of the importance of checking expiry dates and labels of purchased food as they were taught so by their home science teacher. In contrast, with the absence of home science class, it is more likely that children in the wealthier quintiles are more exposed to food and nutrition messages within their families. In focus groups, it emerged that children learn about nutrition in a range of ways: at school, at home, through their families, or by watching television.

In focus groups, children often mentioned the importance of hygiene. Food safety is a priority in the national nutrition policy 2013-2017 (Ministry of Food and Agriculture [MOH] 2013), and has been incorporated into the teaching curriculum. The Ghanaian government, has paid attention to this issue, especially in relation to street food (MOH 2013; FAO 2016). In some interviews, children said that their mothers did not allow them to buy street food due to food safety concerns. Importantly, the focus groups participants in public schools believed that the food available to them during school time was not hygienic but the lack of alternative options meant that they nonetheless buy it.

In the survey and in the focus groups, children uniformly reported that they have healthy foods at home and unhealthy foods at school or in the street, reflecting views food quality. Nevertheless, there are often gaps between taste and food knowledge, with many children mentioning fast foods as their favourite ones. Does nutrition knowledge inform food consumption then? Linear regression analysis suggests that food knowledge is positively associated with dietary diversity but the relationship with food consumption score is insignificant. The results reported in the table below suggest that wealth has a stronger explanatory power for both dietary diversity and food 
consumption. Food consumption appears to be negatively associated with the child's age, which is a result that is difficult to interpret.

Table 4 here

Linear regression analysis does not illuminate important aspects of the relationship. In qualitative interviews, children said that they select foods based on taste and desirability, even if they are unhealthy. Therefore, accessibility, affordability and desirability of food are critical interacting factors. On visits to public schools, we occasionally found that all interviewed children had the same food for lunch because they all bought it from a convenient food stall. For children who buy food with chop money, food needs to be affordable and desirable. We explored children's exposure to food advertisement and found that most children could easily recall food adverts seen on television and on billboards. Many of them were also aware that some adverts target children specifically, using messages that appeal to children, such as the promise of increased energy for sport, catchy colours and memorable jingles. Interestingly, many children doubted of the reliability of advertisements and were particularly sceptical when foods are publicised as healthy and nutritious.

\section{Discussion and conclusions: The urban food security question today}

The results extend several debates on urban food consumption. First, the evidence shows inequality in food quality and food consumption partly driven by socio-economic status. Children from poorer backgrounds are more vulnerable to food insecurity, lower dietary diversity, and poor food consumption. Thus food insecurity, far from being only a rural problem, concerns the urban poor too, and it does so even in the region with the lowest levels of undernutrition nationwide. Low or irregular chop money, which is most likely linked to low and fluctuating household incomes, poses a major obstacle to the ability of children to meet their food needs during the school day, and a group of children in the sample have their first meal at the first or second break during a school day. 
Although it is clear that urban food consumption inequality is driven by wealth, the dynamics are complex. The consumption of packaged and processed foods (among the culprits of rising obesity and associated health problems, see Monteiro et al. 2013) is not only accessible to the wealthier groups of the population, but cuts across wealth groups. These foods tend to be desirable, accessible and relatively affordable. The use of informal distribution channels for packaged foods means they can be bought from street vendors at school and on the roadside, and not only at supermarkets, ensuring their accessibility. With regard to affordability, one comprehensive study on food prices in middle-income countries found that, with the food industry being able to contain costs by using cheap ingredients, the cost of processed foods has either stagnated or fallen while the price of fruit and vegetables has increased over time (Wiggins et al. 2015).

In the 1990s, the question of urban food security was seen as embedded in that of urban poverty (Maxwell 1999). We argue that the urban food question today is defined by two intersecting phenomena: urban inequality and global dietary change. Thus, while the urban poor continue to face the fundamental challenge of adequate food access, a broader definition of urban food security recognises the political economy of food quality and the food industry's role in creating a food environment that provides consumers with unhealthy food options that are widely available, cheap and enticing. Therefore agricultural and food policies that seek to ensure availability of affordable staples for growing urban population through are no longer sufficient. However, Masters et al. (2018) show that food policy across African countries continues to pursue lower food prices. The urban food security question today can be addressed through agricultural, industrial and trade policies that regulate production of cheap, processed, unhealthy foods.

We recognise that our findings are limited by a narrow focus on schoolchildren and more research is needed to grasp the complexity of urban food systems. We also hope that our paper stimulates a debate on the methodological advancements needed to connect micro-level food consumption and macro-level analysis of food systems. We conclude by highlighting two lacunae where future 
research and policy should expand into to enhance our ability to respond to the question of urban food consumption amidst growing inequality and potentially harmful dietary change. First, scholars and policy makers are often guilty of overlooking food processing (Scrinis 2013). This is important as the urban food question and urban poverty are not restricted to issue of food access but also encompass issues of diet quality. Second, while policies that can radically improve food environments are both necessary but complex, enhancing children's food environment at school may be more straightforward. In Ghana there is currently no regulation on the types of food available to children at school. Here the debates on food desert in the North can bring useful insights to policy makers hoping to improve children's food consumption, with potential longlasting benefits for them as future adults. 


\section{Tables}

Table 1. Summary of methods for primary data collection

\begin{tabular}{|c|c|c|}
\hline Phase & Method & Purpose \\
\hline I & $\begin{array}{l}\text { Student survey on food } \\
\text { consumption and nutrition } \\
\text { knowledge (sample }=139 \\
\text { schoolchildren enrolled in JHS) }\end{array}$ & $\begin{aligned} & \text { To gather information on children's } \\
&- \text { Food security } \\
&- \text { Dietary Diversity } \\
&- \text { Food preferences and nutrition knowledge } \\
& \text { - } \text { Food consumption }\end{aligned}$ \\
\hline II & $\begin{array}{l}\text { Focus groups with sub-groups } \\
\text { of survey respondents }\end{array}$ & $\begin{array}{l}\text { To deepen understanding of } \\
\begin{array}{c}\text { - } \\
\text { - }\end{array} \text { Extra-urban mobility and food acquisition } \\
\text { - } \quad \text { Nutrition knowledge and food consumption }\end{array}$ \\
\hline $\begin{array}{l}\text { Cross- } \\
\text { cutting }\end{array}$ & $\begin{array}{l}\text { Semi-structured interviews with } \\
\text { key stakeholders (ministries, } \\
\text { international organisations, food } \\
\text { industry, school and street food } \\
\text { vendors) }\end{array}$ & 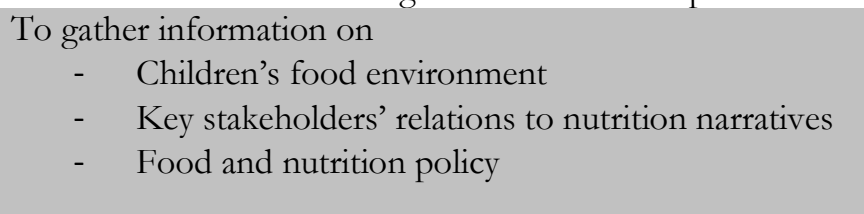 \\
\hline
\end{tabular}

Source: Created by authors

Table 2. Key characteristics of four selected JHS in Accra Metropolitan Area

\begin{tabular}{|c|c|c|c|c|}
\hline School & $\begin{array}{l}\text { Kanda Estate } \\
\text { Cluster }\end{array}$ & Osu Presby ${ }^{2}$ & Jack \& Jill & $\begin{array}{l}\text { Association } \\
\text { International } \\
\text { School (AIS) }\end{array}$ \\
\hline Location & Nima/Kanda & Osu & Roman Ridge & $\begin{array}{l}\text { Airport Residential } \\
\text { Area }\end{array}$ \\
\hline Type & Public & Public & Private & Private \\
\hline Student-teacher ratio & 11.8 & 15.7 & 13.6 & 5.4 \\
\hline $\begin{array}{l}\text { Access to functioning } \\
\text { library }\end{array}$ & No & $\begin{array}{l}\text { Yes (Girls) } \\
\text { No (Boys) }\end{array}$ & Yes & Yes \\
\hline $\begin{array}{l}\text { Access to functioning } \\
\text { computer lab }\end{array}$ & No & No & Yes & Yes \\
\hline $\begin{array}{l}\text { Minimum teaching } \\
\text { equipment }\end{array}$ & Yes & Yes & Yes & Yes \\
\hline $\begin{array}{l}\text { Minimum school } \\
\text { infrastructure }\end{array}$ & No & No & Yes & Yes \\
\hline \multicolumn{5}{|c|}{$\begin{array}{l}\text { Source: Compiled by authors } \\
{ }^{1} \text { Kanda Cluster includes four schools sharing the same courtyard, these are: Ring Road East, Kanda 1, Kanda } 5 \\
\text { and Kanda A.M.A. Data on student-teacher ratio are given as the average across the four schools. } \\
{ }^{2} \text { Osu Presby includes Osu Presby Girls and Osu Presby Boys. Data on student-teacher ratio are given as the } \\
\text { average between the two schools. }\end{array}$} \\
\hline
\end{tabular}

Table 3. Student survey sample

\begin{tabular}{ll}
\hline School & No. of students interviewed \\
\hline Osu Presby Boys and Girls & 32 \\
Kanda Estate Cluster & 30 \\
Jack \& Jill & 31 \\
AIS & 16 \\
TIS & 30 \\
Total & 139 \\
\hline
\end{tabular}

Source: Compiled by authors 
Table 4. Linear regression analysis

Age

Gender

Wealth

Food knowledge

Constant

$\mathbf{R}^{2}$

Observations

Source: Own analysis from survey data

${ }^{*} \mathrm{p}<0.10 * * \mathrm{p}<0.05 * * * \mathrm{p}<0.01$

\section{Child dietary diversity}

$$
\text { b }
$$

Child food consumption score

SE

$-0.118 \quad(0.15)$

$0.615 \quad(0.39)$

$1.621 * * * \quad(0.51)$

$0.948^{*} \quad(0.43)$

$1.331 \quad$ (1.83)

0.120

139

B

$-3.247 * * *$

SE

0.404

$12.267 * * *$

(0.94)

(2.43)

(3.14)

2.35

$34.083 * * *$

0.256

139 


\section{References}

Abdulai, A. G., \& Hulme, D. (2015). The politics of regional inequality in Ghana: State elites, donors and PRSPs. Development Policy Review, 33(5), 529-553.

Abreu, A. J. G. (2012) Migration and Development in Contemporary Guinea-Buissau: A Political Economy Approach, PhD thesis in Economics, SOAS University of London.

Ackah, M., Gyamfi, E. T., Anim, A. K., Osei, J., Hansen, J. K., \& Agyemang, O. (2011). SocioEconomic profile, knowledge of hygiene and food safety practices among street-food vendors in some parts of Accra-Ghana. Internet journal of food safety, 13, 191-197.

Adelman, S., Gilligan, D. and Lehrer, K. (2008). How effective are food for education programs? A critical assessment of the evidence from developing countries (Vol. 9). Washington D.C.: International Food Policy Research Institute.

Aguda, N. D. (2009). Bringing food home: A study on the changing nature of household interaction with urban food markets in Accra, Ghana, Ontario: PhD thesis, Department of Geography, Queen's University.

Agyire-Tettey, F., Ackah, C. G., \& Asuman, D. (2018). An Unconditional Quantile Regression Based Decomposition of Spatial Welfare Inequalities in Ghana. The Journal of Development Studies, 54(3), 537-556.

Amanor, K. S. (2015). Rising powers and rice in Ghana: China, Brazil and African agricultural development. Working Paper, Future Agricultures, (123).

Amanor, K. S., \& Chichava, S. (2016). South-south cooperation, agribusiness, and African agricultural development: Brazil and China in Ghana and Mozambique. World Development, 81, 1323.

Annim, S. K., Mariwah, S., \& Sebu, J. (2012). Spatial inequality and household poverty in Ghana. Economic Systems, 36(4), 487-505.

Arimond, M., Wiesmann, D., Becquey, E., Carriquiry, A., Daniels, M.C., Deitchler, M., FanouFogny, N., Joseph, M.L., Kennedy, G., Martin-Prevel, Y. and Torheim, L.E. (2010). Simple food group diversity indicators predict micronutrient adequacy of women's diets in 5 diverse, resourcepoor settings. The Journal of Nutrition, 140(11), 2059S-2069S.

Arku, G., Luginaah, I., \& Mkandawire, P. (2012). "You Either Pay More Advance Rent or You Move Out": Landlords/Ladies' and Tenants' Dilemmas in the Low-income Housing Market in Accra, Ghana. Urban Studies, 49(14), 3177-3193.

Cooke, E., Hague, S. and McKay, A. (2016). The Ghana poverty and inequality report: Using the $6^{\text {th }}$ Ghana Living Standards Survey. March 2016.

Cudjoe, G., Breisinger, C., \& Diao, X. (2010). Local impacts of a global crisis: Food price transmission, consumer welfare and poverty in Ghana. Food Policy, 35(4), 294-302.

DHS (2014). Demographic and Health Survey 2014. Ghana, Ghana Statistical Service (GSS), Ghana Health Service (GHS), and ICF International. 2015. Rockville, Maryland, USA: GSS, GHS, and ICF International.

Euromonitor International (2019). Passport database, accessed in June 2019. 
FAO (2010). Guidelines for Measuring Individual and Household Dietary Diversity, Rome: Food and Agriculture Organisation.

FAO (2015). The State of Agricultural Commodity Markets. Trade and food security: achieving a better balance between national priorities and the collective good, Rome: Food and Agriculture Organisation.

FAO (2016). Street Food in Urban Ghana. A desktop review and analysis of findings and recommendations from existing literature. Accra: Food and Agriculture Organisation.

Farfan, G., Genoni, M. E., \& Vakis, R. (2015). You are what (and where) you eat: capturing food away from home in welfare measures (No. 7257). The World Bank.

FAOSTAT http://www.fao.org/faostat/en/\#data accessed in April 2017

Filmer, D. \& Pritchett, L. (2001). Estimating Wealth Effects Without Expenditure Data - Or Tears: An Application to Educational Enrolments in States of India', Demography, 38(1), 115-132.

Floro, M. S., \& Swain, R. B. (2013). Food security, gender, and occupational choice among urban low-income households. World Development, 42, 89-99.

Girdner, J., Olorunsola, V., Froning, M., \& Hansen, E. (1980). Ghana's agricultural food policy: Operation feed yourself. Food Policy, 5(1), 14-25.

GHI (2016). Global Hunger Index 2016. Getting to zero hunger, International food Policy Research Institute (IFPRI) and Concern Worldwide.

Gordon, D., Nandy, S., Pantazis, C., Pemberton, S. and Townsend, P. (2003). Child poverty in the developing world. Policy Press.

GSS (2015). Ghana poverty mapping report. Ghana Statistical Service, 2015.

Hannum, E., Liu, R., \& Alvarado-Urbina, A. (2017). Evolving approaches to the study of childhood poverty and education. Comparative Education, 53(1), 81-114.

Hawkes, C. (2006). Uneven dietary development: linking the policies and processes of globalization with the nutrition transition, obesity and diet-related chronic diseases. Globalization and health, 2(1), 4.

Hawkes, C., Blouin, C., Henson, S., Drager, N., \& Dubé, L. eds. (2010). Trade, food, diet and health: perspectives and policy options. Oxford: John Wiley \& Sons.

Hawkes, C. and Murphy, S. (2010). 'An overview of global food trade', in Hawkes, C., Blouin, C., Henson, S., Drager, N., \& Dubé, L. eds. (2010). Trade, food, diet and health: perspectives and policy options. Oxford: John Wiley \& Sons.

Hawkesworth, S., Dangour, A. D., Johnston, D., Lock, K., Poole, N., Rushton, J., Uauy, R. \& Waage, J. (2010). Feeding the world healthily: the challenge of measuring the effects of agriculture on health. Philosophical Transactions of the Royal Society of London B: Biological Sciences, 365(1554), 30833097.

IFPRI (2016). Global nutrition report. From promise to impact: ending malnutrition by 2030, Washington D.C. 
Imamura, F., Micha, R., Khatibzadeh, S., Fahimi, S., Shi, P., Powles, J. and Mozaffarian, D. (2015). Dietary quality among men and women in 187 countries in 1990 and 2010: a systematic assessment. The Lancet Global Health, 3(3), e132-e142.

Imdad, A., Yawar Yakoob, M. and Bhutta, Z. A. (2011) Impact of maternal education about complementary feeding and provision of complementary foods on child growth in developing countries. BMC Public Health, 11(Suppl. 3):S25.

Jerven, M. (2016). Research Note: Africa by numbers: Reviewing the database approach to studying African economies. African Affairs, 115(459), 342-358.

Johnston, D., \& Abreu, A. (2016). The asset debates: How (not) to use asset indices to measure well-being and the middle class in Africa. African Affairs, adw019.

Kollamparambil, U. (2017). Impact of internal in-migration on income inequality in receiving areas: A district level study of South Africa. The Journal of Development Studies, 53(12), 2145-2163.

Lagerkvist, C. J., Hess, S., Okello, J., \& Karanja, N. (2013). Consumer willingness to pay for safer vegetables in urban markets of a developing country: The case of Kale in Nairobi, Kenya. The Journal of Development Studies, 49(3), 365-382.

Lentz, C. (2015). 'Elites Or Middle Classes?: Lessons from Transnational Research for the Study of Social Stratification in Africa'. Working Papers of the Department of Anthropology and African Studies of the Johannes Gutenberg University Mainz 161.

Lerner, A., Sweeney, S., \& Eakin, H. (2014). Growing buildings in corn fields: Urban expansion and the persistence of maize in the Toluca Metropolitan Area, Mexico. Urban Studies, 51(10), 21852201.

Levin, C. E., Ruel, M. T., Morris, S. S., Maxwell, D. G., Armar-Klemesu, M., \& Ahiadeke, C. (1999). Working women in an urban setting: traders, vendors and food security in Accra. World Development, 27(11), 1977-1991.

Luckham, R., Gyimah-Boadi, E., Ahadzie, W. and Boateng, N. (2005). The middle classes and their role in national development. CDD/ODI Policy Brief No. 3, November 2005.

Masters, W. A., Rosenblum, N. Z., \& Alemu, R. G. (2018). Agricultural transformation, nutrition transition and food policy in Africa: Preston curves reveal new stylised facts. The Journal of Development Studies, 54(5), 788-802.

Maxwell, D. (1999). The political economy of urban food security in Sub-Saharan Africa. World Development, 27(11), 1939-1953.

Maxwell, D., Levin, C., Armar-Klemesu, M., Ruel, M., Morris, S., \& Ahiadeke, C. (2000). Urban liveliboods and food and nutrition security in Greater Accra, Ghana. Washington, DC: International Food Policy Research Institute.

MOH (2013). National Nutrition Policy 2013-2017, Accra: Ministry of Health.

Molina, E. and Martin, G. (2015). Education service delivery in Mozambique. World Bank, October 2015.

Monteiro, C. A., Moubarac, J. C., Cannon, G., Ng, S. W., \& Popkin, B. (2013). Ultra-processed products are becoming dominant in the global food system. Obesity reviews, 14(S2), 21-28. 
Nyanteng, V. K. and Wayo Seini, A. (2000). 'Agricultural policy and the impact on growth and productivity in 1970-1995', in Aryeetey, E., Harrigan, J., \& Nissanke, M. eds. (2000). Economic reforms in Ghana: The miracle and the mirage. Africa World Press.

Obeng-Odoom, F. (2012). Neoliberalism and the urban economy in Ghana: Urban employment, inequality, and poverty. Growth and Change, 43(1), 85-109.

Ofori-Asenso, R., Agyeman, A. A., Laar, A., \& Boateng, D. (2016). Overweight and obesity epidemic in Ghana_a systematic review and meta-analysis. BMC Public Health, 16(1), 1239.

Ouma, S. (2015) Export Markets: The Making and Unmaking of Global Food Connection in West Africa, Chichester, UK: John Wiley.

Popkin, B. M., Adair, L. S., \& Ng, S. W. (2012). Global nutrition transition and the pandemic of obesity in developing countries. Nutrition reviews, 70(1), 3-21.

Ruel, M. T. (2002) 'Is dietary diversity an indicator of food security or dietary quality? A review of measurement issues and research needs', FCND Discussion 319.

Scrinis, G. (2013). Nutritionism: the science and politics of dietary advice, New York: Columbia University Press.

UNDP Ghana (2015). Ghana Millenium Development Goals. Report. September 2015.

Vyas, S., \& Kumaranayake, L. (2006). Constructing socio-economic status indices: how to use principal components analysis. Health Policy and Planning,21(6), 459-468.

Wall, M., \& Johnston, D. (2008). Counting Heads or Counting Televisions: Can Asset-based Measures of Welfare Assist Policy-makers in Russia?. Journal of Human Development, 9(1), 131-147.

WFP (2008). Food consumption analysis Calculation and use of the food consumption score in food security analysis, Rome: World Food Programme.

WHO (2012). Global school-based student health survey. Junior High Schools Report, World Health Organisation.

Wiggins, S. et al. (2015). The rising cost of a healthy diet Changing relative prices of foods in highincome and emerging economies, London, Overseas Development Institute (ODI).

\footnotetext{
i The GHI is compiled by the International Food Policy Research Institute (IFPRI) combining four indicators: FAO prevalence of undernourishment, child stunting, child wasting and child mortality. The GHI is considered to be a good proxy of hidden hunger, linked to micronutrient imbalances.

ii It is recognised that the national statistics on food production and trade compiled by the Food and Agriculture Organisation (FAO) are subject to errors. The quality of this data is especially low for poorer countries, where data gaps are filled with model-based estimations, which often differ substantially from actual production and trade volumes (Hawkesworth et al. 2010). These statistics may be useful to describe some broad patterns of food production and trade, but given their limitations they should only be used in combination with other evidence.

iii Packaged food includes cooking ingredients, dairy products and baby food, snacks and staple foods.

iv On $19^{\text {th }}$ January 2016, Ghana Web reports that the total revenue for the three most important export commodities - oil, gold and cocoa - has declined by 2.4 billion USD between 2014 and 2015.

v Minimum teaching equipment and minimum school infrastructure are two World Bank's Service Delivery Indicators (Molina and Martin 2015) used to assess the delivery of education and health. Minimum teaching resources captures availability of (i) whether a random classroom has a functioning blackboard and chalk, (ii) the share of students with pens, and (iii)
} 
the share of students with notebooks. Minimum infrastructure resources reflects availability of (i) functioning toilets operationalized as being clean, private, and accessible (ii) sufficient light to read the blackboard from the back of the classroom. The indicators, operationalized as binary, are based on researchers' observation of selected schools.

vi Classifying schools was preferable to classifying neighbourhoods due to lack of locality data and intra-locality heterogeneity (Maxwell et al. 2000), as well as the fact that children going to private schools tend not to live in the school area.

vii We considered the possibility that teacher's participation could introduce a bias towards higher-achieving pupils. However, respondents obtained a thank-you gift of pens and pencils, it was also possible teachers would prioritise children from more vulnerable backgrounds. Thus, overall it is hard to identify an overall bias.

viii It is an adapted FCS because we did not collect all data to calculate the full FCS. We have information on a smaller number of food items grouped in five food groups - fruit, vegetables, dairy, meat/fish, and sugar. Therefore we did not calculate a score but instead used the continuum variable based on the weightings provided by WFP (2008).

ix Most children interviewed at Kanda Estate reported that they buy food from the food vendors across the road from the school, where there is also a mini bus (trotro) station and there are more options.

$x$ Five children said that they do not receive chop money on a daily basis, and therefore they need to spread the available cash over two or three days. At Kanda Estate, the teachers told us that, if there is any left-over food from the School Feeding Programme in the primary schools (which are in the same buildings), they give it to children in JHS who struggle to buy their own food.

xi We note that the question has a subjective character and may have captured, in some cases, feeling hungry due to circumstantial lack of food rather than real lack of resources to acquire food.

xii The exact number of FanMilk street vendors is unknown because they are not employed by FanMilk, but considered to be independent vendors, fully operating in the informal economy. The structure of employment is similar to that becoming prominent in the gig economy: vendors are given equipment (so they are recognisable on the streets) and training by FanMilk but they are nonetheless treated as self-employed. 
